\title{
Article \\ Exploring Shank Circumference by Stretching after Training among Volleyball Players
}

\author{
Yi-Lang Chen * (1), Fang-Min Tsai, Wei-Chen Hsu, Chun-Ju Yang and Ting-Yo Yei
}

check for updates

Citation: Chen, Y.-L.; Tsai, F.-M.; Hsu, W.-C.; Yang, C.-J.; Yei, T.-Y. Exploring Shank Circumference by Stretching after Training among Volleyball Players. Int. J. Environ. Res. Public Health 2021, 18, 8849. https://doi.org/10.3390/ijerph 18168849

Academic Editors: Beat Knechtle and Mário António Cardoso Marques

Received: 16 June 2021

Accepted: 20 August 2021

Published: 22 August 2021

Publisher's Note: MDPI stays neutral with regard to jurisdictional claims in published maps and institutional affiliations.

Copyright: (c) 2021 by the authors. Licensee MDPI, Basel, Switzerland. This article is an open access article distributed under the terms and conditions of the Creative Commons Attribution (CC BY) license (https:// creativecommons.org/licenses/by/ $4.0 /)$.
Department of Industrial Engineering and Management, Ming Chi University of Technology, New Taipei 24301, Taiwan; m09218014@mail2.mcut.edu.tw (F.-M.T.); m09218003@mail2.mcut.edu.tw (W.-C.H.); m09218009@mail2.mcut.edu.tw (C.-J.Y.); m09218010@mail2.mcut.edu.tw (T.-Y.Y.)

* Correspondence: ylchen@mail.mcut.edu.tw

Abstract: This preliminary study examined the effects of a stretching intervention after training and its duration (15 vs. $30 \mathrm{~min}$ ) on participants' shank circumference (SC) reduction and subjective discomfort score. Ten male volleyball players underwent a routine $3 \mathrm{~h}$ training. A two-way analysis of variance revealed that the stretching intervention had significant effects on SC reduction $(p<0.01)$ and subjective discomfort scores $(p<0.001)$. Stretching after training could help eliminate shank strain, and a slighter discomfort in shanks when stretching was also seen (score, 20.1/100). An independent-samples $t$ test revealed a significantly higher SC reduction $(p<0.01)$ with 30 min of stretching $(5.6 \mathrm{~mm})$ than with $15 \mathrm{~min}$ of stretching $(2.7 \mathrm{~mm})$; both stretching durations reduced SC significantly more than the no-stretching condition did. The findings of this study can serve as a reference for volleyball players to alleviate shank strain after daily routine training.

Keywords: stretching; shank circumference reduction; intervention time; subjective discomfort

\section{Introduction}

Many athletes experience muscle soreness after intense exercise. Intensive muscle contractions (e.g., eccentric exercise) cause damage to muscle fibers [1] and may result in delayed-onset muscle soreness (DOMS) [2-4]. Many interventions, including stretching, massage, cryotherapy, laser therapy, nutritional strategies, proper sleep, ultrasound, pharmacological agents, and cool water immersion [3,5-9], have been used to prevent these symptoms. However, which recovery modalities are most effective is still questionable, especially with regard to the varying features of individual sports and athletes $[9,10]$.

Volleyball consists of periods of low intensity followed by short bouts of high-intensity force application [11]. Players must dive, abruptly jump repeatedly, and change direction quickly, all of which involve intense eccentric muscle contractions. This intense muscular work can cause fatigue and thus affect players' performance [7]. The recovery modalities utilized after volleyball competition or training thus become important in preventing injury, especially when athletes have little time between intensive trainings or even matches. Even though volleyball is popular worldwide, little research has examined recovery strategies for volleyball players [12].

A systematic literature review by Closs et al. [13] highlighted the specific methods used to recover after playing volleyball and evaluated their effectiveness. They found that some methods, such as nutrition and sleep regimens, have been definitively shown to benefit volleyball players, whereas others, such as cold water immersion and laser therapy, have shown promise but require further study to determine their overall effect. Unfortunately, the strategy of stretching for recovery was not included among these methods because very few published studies have been conducted on stretching recovery in volleyball players. Nevertheless, Barnett [5] surveyed the recovery modalities used between training sessions by elite athletes and speculated that the majority of studies assessing exercise-induced 
muscle injury and DOMS have used untrained participants performing unfamiliar eccentric exercise. Thus, the results may be unlikely to reflect the actual situations of these athletes.

Some recovery techniques, such as nutrition and sleep modalities, should be monitored by athletes themselves on an individual level, and their condition and response to recovery may not be significant until days or weeks later [13]. However, some studies examining the efficacy of recovery techniques have focused on exercise-induced muscle damage (e.g., DOMS) and pain or discomfort 1-2 days after exercising; one recovery technique is stretching [14-17]. Stretching has long been a common modality before and after training during different exercise stages [18]. The efficacy of stretching as an aid to performance is less apparent; however, the benefit may lie in the alleviation of discomfort and pain [16,19]. Particularly, chronic stretching may reduce injury [18].

The primary perceived function of stretching has been to increase the range of motion of the joints and to reduce musculotendinous stiffness to prevent injury and promote recovery [16,20-22]. For example, in French professional soccer, 50\% of teams currently use stretching as a recovery strategy [15]. Although a mechanism by which stretching may enhance the recovery process has yet to be identified, stretching may disperse the swelling accumulated during tissue damage [23]. To assess the degree of swelling, studies [24-26] have employed an indicator to measure changes in shank circumference (SC). Increased SC indicates that leg strain is exacerbated because of increased accumulation of blood in the lower limbs due to restricted circulation [27], particularly within the perimuscular connective tissue and regions of the myotendinous junction, because of eccentric exercise $[4,28]$. Such swelling is characteristic of an acute inflammatory response to muscle damage or injury [29].

Because the recovery technique of stretching has been rarely evaluated in professional volleyball players, this study recruited 10 participants from a university volleyball team in Taiwan to examine the recovery effect of stretching on alleviating leg strain after regular daily training. Independent variables were stretching exercises (stretching vs. nonstretching) and time periods of stretching (15 vs. $30 \mathrm{~min})$. SC reductions and subjective discomfort scores were collected in varying combinations as dependent variables to examine the effect of stretching on leg strain alleviation in volleyball players.

\section{Materials and Methods}

\subsection{Participants}

This study recruited 10 healthy male participants, all of whom were active volleyball players on a university team who were recommended for admission on the basis of their volleyball skill. The team qualifies for the National College Cup finals in Taiwan almost every year. The mean (standard deviation (SD)) age, height, body weight, and body mass index of the participants were 23.5 (1.6) y, $185.4(4.7) \mathrm{cm}, 78.8$ (5.1) kg, and 22.9 (1.5) $\mathrm{kg} / \mathrm{m} 2$, respectively. All participants were spikers; one participant jumps with his right foot and all others jump on their left feet. SC measurement was based on the jumping foot. Although the participants have experienced muscle soreness because of regular training or competition, the soreness was all reasonable as a postexercise effect. In the six months before the experiment, none of the participants sought any medical attention due to pain or injury. Prior to the test, all participants were informed of the experimental procedure of this study. The experiment was performed in accordance with the principles of the Declaration of Helsinki [30], and the Ethics Committee of National Taiwan University approved the experimental procedures. All study participants provided written consent before the experiment and received remuneration for participation.

\subsection{Stretching Protocols}

The stretching exercises adopted in this study flexed and extended various body parts, particularly the legs. Four stretching protocols, which mainly included standing, sitting, and lying hamstring stretches [31-34], were implemented with reference to the long-term practice of the university volleyball team: 
1. Standing stretching: Participants stood with their hands against a wall, then alternately lifted their right and left toes against the wall to stretch their hamstrings (Figure 1a).

2. Sitting stretch (I): Participants sat on the floor and kept their legs straight, then bent their trunk forward and reached their hands as close as possible to their toes (Figure 1b).

3. Sitting stretch (II): Participants sat on the floor and flexed their legs such that their knees were close to the ground; they used their hands to help make the soles of their feet touch completely flat against each other. Participants bent their trunk forward as far as possible (Figure 1c).

4. Lying-down stretching: Participants laid on the floor and lifted a single leg, using their hands to bend the leg toward their face as far as possible. They then switched legs (Figure 1d).
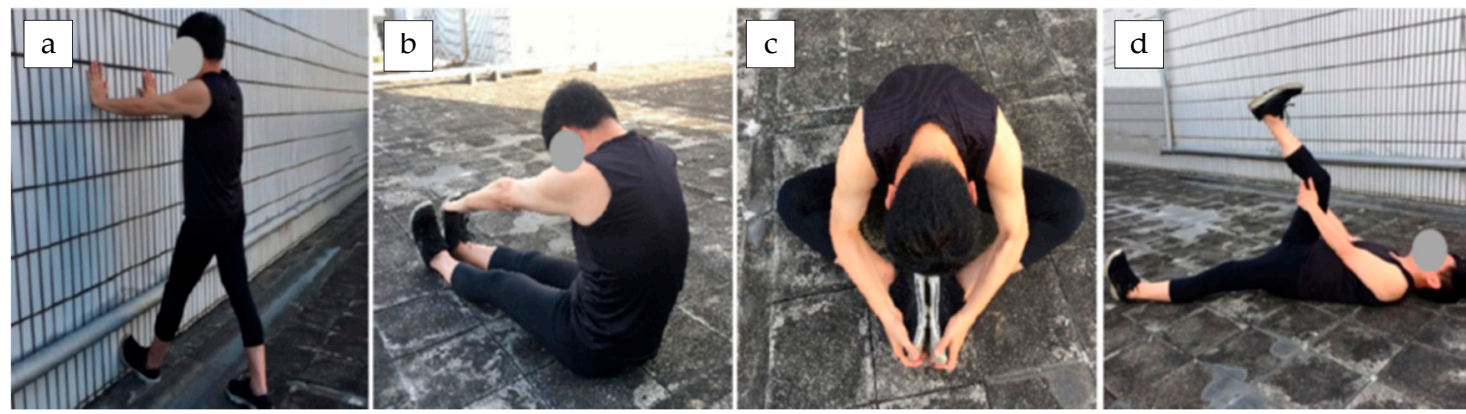

Figure 1. Four stretching protocols (a-d) after volleyball training used in this study.

During stretching, each of the 4 protocols were performed over $1 \mathrm{~min}$ and repeated until the participants were instructed to stop stretching. Stretching frequency was controlled using a digital metronome for a total bout of stretching of $15 \mathrm{~s}$ (stretching followed by resting, $7.5 \mathrm{~s}$ of each) for trunk flexion, hamstring extension, or leg/foot lifting. The 4 stretching bouts were performed by participants over $1 \mathrm{~min}$ and repeated.

\subsection{SC Measurement}

On the basis of the SC measurements proposed in previous studies [24,25], we used a pull-push tester (MP-1; Attonic, Aichi, Japan) to control the fixed force applied during the measurement to minimize errors. We measured the participants' SC at the midpoint between the knee and ankle joints (the point was marked during the whole testing period). During SC measurement, participants were asked to stand on the ground, and each SC measurement was repeated three times. The average of the two closest values was then used for further analyses.

\subsection{Visual Analog Scale for Discomfort Rating}

In this study, subjective assessments of lower limb discomfort were performed using a continuous visual analog scale (VAS) [35]. The VAS has been reported to be a reliable assessment of perception and more precise than an ordinal scale that ranks responses; the VAS used in the present study was modeled after the comfort scales developed by Mündermann et al. [36]. The left end of the scale was labeled "No discomfort at all", and the right end was labeled "Extreme discomfort". The participants used a pen to complete ratings by marking locations along the scale that most accurately represented their feeling of discomfort. An experimenter used a ruler to measure the distance from the "No discomfort at all" anchor to the location of a mark, and this distance was used for analysis. 


\subsection{Experimental Design and Procedure}

This study collected SC values and subjective discomfort scores for the lower limbs with two stretching conditions (with and without stretching) after training and two stretching or no-stretching durations (15 and $30 \mathrm{~min}$; SC and VAS values were collected at these two time points). The ten participants were randomly divided into two groups (groups A and B) with five participants each (Figure 2). After regular daily training from 18:30 to 21:30, the participants in groups A and B were asked to perform stretching and nonstretching trials, respectively. The SC values were collected for each group before and after training $(0 \mathrm{~min})$ and the subsequent stretching or resting period at 15 and $30 \mathrm{~min}$. The VAS measurements were reported by participants only after 15 and $30 \mathrm{~min}$. The participants in group B (resting group) were requested to sit on the floor without any effort. On the next day, the two groups were alternated. The process was repeated twice, and the average value in SC of each participant was used for further analyses. All SC reductions were calculated on the basis of data measurements of each participant.

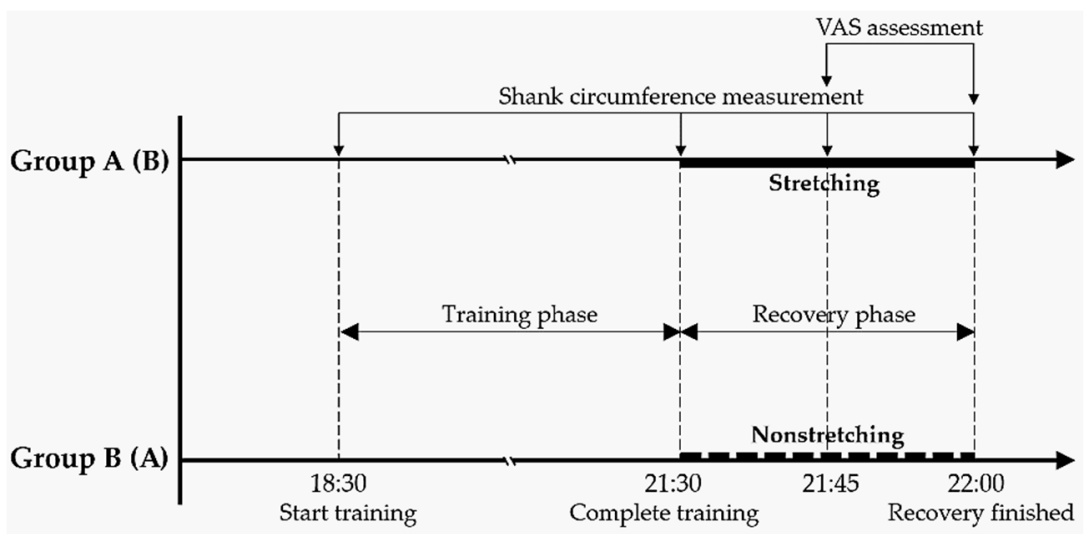

Figure 2. Schematic timeline of study design (VAS, visual analog scale).

\subsection{Statistical Analysis}

The data collected in the study were analyzed using SPSS Statistics 23.0 (IBM Corp., Armonk, NY, USA), and a significance level of $\alpha=0.05$ was used for all tests. Data collected from the participants were analyzed using descriptive statistics (i.e., mean, SD, and independent-samples $t$ test). Two-way analysis of variance (ANOVA) was used to examine the effects of the two stretching conditions (with and without stretching) and the two time periods ( 15 and $30 \mathrm{~min}$ ) on SC reduction and VAS values. However, the SC reduction was calculated on the basis of $\mathrm{SC}$ data recorded when training was completed.

\section{Results}

The two-way ANOVA revealed that both stretching $(p<0.01)$ and stretching duration $(p<0.05)$ significantly reduced SC (Table 1), and stretching for $30 \mathrm{~min}$ was associated with a high SC reduction (Figure 3). Subjective discomfort scores were significantly influenced by stretching $(p<0.001)$ but not by stretching duration. The overall mean (SD) discomfort score reported by the stretching group (20.1 [22.0]) was higher than that reported by the no-stretching group (7.8 [10.0]).

Table 1. Two-way analysis of variance results.

\begin{tabular}{ccccccc}
\hline Responses & Variables & $d f$ & MS & $\boldsymbol{F}$ & Significance & Power \\
\hline \multirow{3}{*}{ Shank circumference reduction } & Stretching (S) & 1 & 93.52 & 8.74 & $p<0.01$ & 0.792 \\
& Time period (T) & 1 & 59.48 & 4.62 & $p<0.05$ & 0.747 \\
& S $\times$ T & 1 & 12.07 & 0.95 & $p=0.333$ & 0.161 \\
\hline \multirow{2}{*}{ Discomfort score } & Stretching (S) & 1 & 2919.96 & 10.04 & $p<0.001$ & 0.878 \\
& Time period (T) & 1 & 231.50 & 0.80 & $p=0.375$ & 0.142 \\
& S $\times$ T & 1 & 48.54 & 0.17 & $p=0.684$ & 0.069 \\
\hline
\end{tabular}




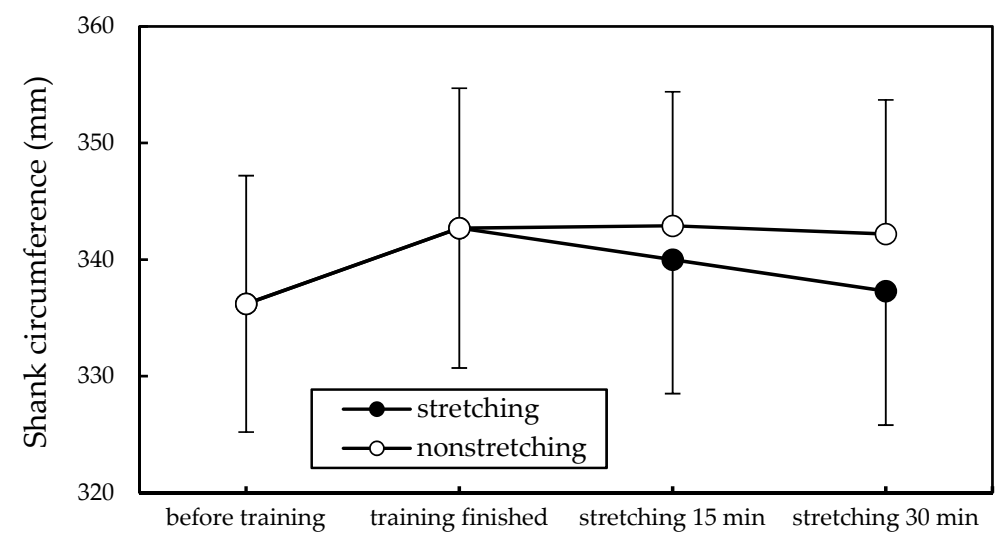

Figure 3. Comparison of shank circumferences (mean with standard deviation) at different measurement stages.

Table 2 shows the $t$ test results of various test conditions in pairs. When stretching was performed, the effect of stretching for $30 \mathrm{~min}$ on participants' SC reduction significantly increased compared with the effect of stretching for $15 \mathrm{~min}(p<0.01)$, with a difference of $2.9 \mathrm{~mm}$. The SC reduction in the no-stretching condition was also higher at $30 \mathrm{~min}$ than at $15 \mathrm{~min}$; however, this finding was not significant. Regardless of duration, SC reduction with stretching was significantly higher than without stretching.

Table 2. Shank circumference reduction between various testing combinations (in $\mathrm{mm}$ ).

\begin{tabular}{cccc}
\hline Levels & Stretching & No-Stretching & $t$ Test Results \\
\hline $15 \mathrm{~min}$ & $2.7(1.4)$ & $-0.2(1.0)$ & $t=5.839, p<0.001$ \\
$30 \mathrm{~min}$ & $5.6(2.1)$ & $0.5(1.7)$ & $t=6.487, p<0.001$ \\
\cline { 1 - 3 }$t$ test results & $t=-4.525, p<0.01$ & $t=1.350, p=0.195$ & \\
\hline
\end{tabular}

\section{Discussion}

This study is the first to examine the effect of stretching on alleviating lower extremity strain after volleyball training. Reduction in SC was considered an index of eliminated strain. The results show that stretching after training had benefits for SC reduction and that the duration also affected the degree of SC reduction. Stretching for a longer time (30 $\mathrm{min}$ in this study) could lead to better $\mathrm{SC}$ reduction.

Figure 3 illustrates the alterations of SC at various measurement points. The SC of participants increased from $336.2 \mathrm{~mm}$ before training to $342.7 \mathrm{~mm}$ after training for $3 \mathrm{~h}$. However, the non-stretching SC values hardly changed within $30 \mathrm{~min}$ after training, whereas stretching reduced the SC to $340.0 \mathrm{~mm}$ and $337.3 \mathrm{~mm}$ at 15 and $30 \mathrm{~min}$, respectively. The SC recovered and was slightly greater than before training, with a difference of $1.1 \mathrm{~mm}$. The SD in Figure 3 appeared high because of the individual differences in SC values. All SC reductions were calculated on the basis of measurements of each participant to minimize the effect of the variation between individuals.

Bobbert et al. [23] proposed that the static stretching of sore muscles after exercise can force the dispersion of swelling that accumulates after tissue damage. Repeated stretching reduces tension on the muscle-tendon unit at any given length. Stretching may be the most effective means of alleviating pain during DOMS. Because the jumping attack in volleyball is the primary source of strain on an athlete's body, especially the legs, we adopted SC as an indicator of leg strain (swelling) [24,26]. Stretching has been demonstrated to have no effect on the alleviation of muscle soreness or other DOMS symptoms in previous studies. Cheung et al. [3] stated that one explanation is that studies employing stretches of less than $30 \mathrm{~s}$ may be limited by the stretch reflex response. Only minimal stretching lasting 0 to $5 \mathrm{~min}$ has been generally reported in stretching studies [3]. Stone et al. [18] also indicated that acute stretching has little effect on injury, whereas chronic stretching 
may. The Premier League reported a mean static stretching holding time of approximately $30 \mathrm{~s}$ and a mean number of repetitions per hamstring muscle group of 3 per session. In French professional soccer, even though 50\% of teams currently use stretching as a recovery strategy [15], no substantial scientific evidence has supported the use of stretching to enhance the postexercise recovery of soccer players [37]. In the present study, stretching was followed immediately by volleyball training and implemented continuously for longer periods, and SC reductions were examined at the middle $(15 \mathrm{~min})$ and final $(30 \mathrm{~min})$ points of the whole period.

Our findings also reveal that the subjective discomfort score with no stretching (i.e., seated resting) was significantly lower than that with stretching (7.8 vs. 20.1). However, the VAS score is designated on a scale from 0 to $100 \mathrm{~mm}$ with the anchors of 0 for "No discomfort at all" to 100 for "Extreme discomfort". In other words, a score of 20 was a slightly uncomfortable level [36]. Compared with the effect on SC reduction, stretching after training is still of practical value.

Recovery techniques after volleyball training tend to have long-term effects (nutritional strategies, proper sleep, mental and psychological techniques) and some short-term effects (cold water immersion and laser therapy), but no relevant research has been conducted on stretching [13]. Herbert et al. [38] reported that stretching was not clinically worthwhile for reducing muscle soreness in the days after exercise; however, they did not perform an immediate intervention after training. Studies have also found that on the basis of differences in physical characteristics, the recovery effects between untrained people and professional athletes vary $[5,15]$. The four stretching protocols adopted in the present study were developed and modified based on stretching techniques used for years by the university volleyball team. Some volleyball team members had questioned the effect of stretching, which motivated us to conduct the study.

This study has several limitations. First, it was limited by the qualifications of the participants. Only 10 active attackers from the university volleyball team were recruited; this sample size is limited to a single team and is relatively small. A multi-site study would allow an increase in subject numbers for future research. In addition, this study was a cross-sectional study that extended the findings for the DOMS effect or fatigue recovery, but further investigation is needed. SC reduction was used as an indicator of leg strain; whether its representativeness was sufficient requires more examination for clarification.

\section{Conclusions}

This preliminary study recruited 10 university volleyball players to examine the effect of stretching on SC reduction after training. The results showed that stretching had a significant effect on reducing SC. Although stretching may cause some discomfort, SC reduction differed significantly between $15 \mathrm{~min}$ of stretching and no stretching, and SC reduction was optimal with stretching for $30 \mathrm{~min}$.

Author Contributions: Conceptualization, Y.-L.C.; methodology, Y.-L.C.; validation, Y.-L.C.; formal analysis, F.-M.T., W.-C.H., C.-J.Y. and T.-Y.Y.; investigation, F.-M.T., W.-C.H., C.-J.Y. and T.-Y.Y.; resources, Y.-L.C.; data curation, F.-M.T.; writing—original draft preparation, F.-M.T. and T.-Y.Y.; writing—review and editing, Y.-L.C.; visualization, Y.-L.C.; supervision, Y.-L.C.; project administration, Y.-L.C.; funding acquisition, Y.-L.C. All authors have read and agreed to the published version of the manuscript.

Funding: This research was partially funded by the Ministry of Science and Technology (MOST), Taiwan, grant number 107-2221-E-131-021-MY3 and the APC was funded by MOST.

Institutional Review Board Statement: The study was conducted according to the guidelines of the Declaration of Helsinki, and approved by the Ethics Committee of National Taiwan University (2017/12/EM014).

Informed Consent Statement: Informed consent was obtained from all subjects involved in the study. 
Data Availability Statement: The data presented in this study are available on request from the corresponding author. The data are not publicly available due to privacy reasons.

Acknowledgments: The authors wish to acknowledge all participants for their support of the study.

Conflicts of Interest: The authors declare no conflict of interest.

\section{References}

1. Proske, U.; Morgan, D.L. Muscle damage from eccentric exercise: Mechanism, mechanical signs, adaptation and clinical applications. J. Physiol. Phys. 2001, 537, 333-345. [CrossRef]

2. Armstrong, R.B. Mechanisms of exercise-induced delayed onset muscular soreness: A brief review. Med. Sci. Sports Exerc. 1984, 16, 529-538. [CrossRef] [PubMed]

3. Cheung, K.; Hume, P.; Maxwell, L. Delayed onset muscle soreness: Treatment strategies and performance factors. Sports Med. 2003, 33, 145-164. [CrossRef] [PubMed]

4. Cleak, M.J.; Eston, R.G. Muscle soreness, swelling, stiffness and strength loss after intense eccentric exercise. Br. J. Sports Med. 1992, 26, 267-272. [CrossRef] [PubMed]

5. Barnett, A. Using recovery modalities between training sessions in elite athletes—Does it help? Sports Med. 2006, 36, 781-796. [CrossRef] [PubMed]

6. Klich, S.; Krymski, I.; Michalik, K.; Kawczyński, A. Effect of short-term cold-water immersion on muscle pain sensitivity in elite track cyclists. Phys. Ther. Sport 2018, 32, 42-47. [CrossRef]

7. Harty, P.S.; Cottet, M.L.; Malloy, J.K.; Kerksick, C.M. Nutritional and supplementation strategies to prevent and attenuate exercise-induced muscle damage: A brief review. Sports Med.-Open 2019, 5, 1-17. [CrossRef]

8. Altarriba-Bartes, A.; Peña, J.; Vicens-Bordas, J.; Casals, M.; Peirau, X.; Calleja-González, J. The use of recovery strategies by Spanish first division soccer teams: A cross-sectional survey. Phys. Sportsmed. 2020, 1-11. [CrossRef]

9. Bishop, P.A.; Jones, E.; Woods, A.K. Recovery from training: A brief review. J. Strength Cond. Res. 2008, 22, 1015-1024. [CrossRef]

10. Santos, C.X.; Beltrão, N.B.; Pirauá, A.L.T.; Durigan, J.L.Q.; Behm, D.; de Araújo, R.C. Static stretching intensity does not influence acute range of motion, passive torque, and muscle architecture. J. Sport Rehabil. 2020, 29, 1-6. [CrossRef]

11. Koley, S.; Kaur, S.P. Correlations of handgrip strength with selected hand-arm-anthropometric variables in Indian inter-university female volleyball players. Asian J. Sports Med. 2011, 2, 220-226. [CrossRef] [PubMed]

12. Vanderlei, F.; Bastos, F.; Tsutsumi, G.Y.C.; Vanderlei, L.C.M.; Júnior, J.N.; Pastre, C.M. Characteristics and contributing factors related to sports injuries in young volleyball players. BMC Res. Notes 2013, 6, 415. [CrossRef]

13. Closs, B.; Burkett, C.; Trojan, J.D.; Brown, S.M.; Mulcahey, M.K. Recovery after volleyball: A narrative review. Phys. Sportsmed. 2020, 48, 8-16. [CrossRef] [PubMed]

14. Nelson, A.G.; Driscoll, N.M.; Landin, D.K.; Young, M.A.; Schexnayder, I.C. Acute effects of passive muscle stretching on sprint performance. J. Sports Sci. 2005, 23, 449-454. [CrossRef]

15. Nédélec, M.; McCall, A.; Carling, C.; Legall, F.; Berthoin, S.; Dupont, G. Recovery in soccer. Sports Med. 2012, 42, 997-1015. [CrossRef]

16. Behm, D.G.; Blazevich, A.J.; Kay, A.D.; McHugh, M. Acute effects of muscle stretching on physical performance, range of motion, and injury incidence in healthy active individuals: A systematic review. Appl. Physiol. Nutr. Metab. 2016, 41, 1-11. [CrossRef]

17. Babault, N.; Rodot, G.; Champelovier, M.; Ometti, C. A survey on stretching practices in women and men from various sports or physical activity programs. Int. J. Environ. Res. Public Health 2021, 18, 3928. [CrossRef] [PubMed]

18. Stone, M.; Ramsey, M.W.; Kinser, A.M.; O’Bryant, H.S.; Ayers, C.; Sands, W.A. Stretching: Acute and chronic? The potential consequences. Strength Cond. J. 2006, 28, 66-74. [CrossRef]

19. Villanueva, A.; Rabal-Pelay, J.; Berzosa, C.; Gutiérrez, H.; Cimarras-Otal, C.; Lacarcel-Tejero, B.; Bataller-Cervero, A.V. Effect of a long exercise program in the reduction of musculoskeletal discomfort in office workers. Int. J. Environ. Res. Public Health 2020, 17, 9042. [CrossRef]

20. Kay, A.D.; Blazevich, A.J. Reductions in active plantarflexor moment are significantly correlated with static stretch duration. Eur. J. Sport Sci. 2008, 8, 41-46. [CrossRef]

21. McHugh, M.P.; Cosgrave, C.H. To stretch or not to stretch: The role of stretching in injury prevention and performance. Scand. J. Med. Sci. Sports 2010, 20, 169-181. [CrossRef] [PubMed]

22. Page, P. Current concepts in muscle stretching for exercise and rehabilitation. Int. J. Sports Phys. Ther. 2012, 7, 109-119. [PubMed]

23. Bobbert, M.F.; Hollander, A.P.; Huijing, P.A. Factors in delayed onset muscular soreness of man. Med. Sci. Sports Exerc. 1986, 18, 75-81. [CrossRef]

24. Lin, Y.-H.; Chen, C.-Y.; Cho, M.-H. Influence of shoe/floor conditions on lower leg circumference and subjective discomfort during prolonged standing. Appl. Egon. 2012, 43, 965-970. [CrossRef] [PubMed]

25. Chen, Y.-L.; Cheng, Y.-T.; Ye, J.-N.; Huang, T.-L.; Chen, W.-N. Posture and time arrangement influence shank circumference reduction when performing leg raising exercise. Int. J. Environ. Res. Public Health 2020, 17, 5735. [CrossRef]

26. Chen, Y.-L.; Wu, B.-Z.; Huang, D.-H. Effect of participant physiques on increases in shank circumference for the two prolonged standing conditions. Hum. Factors Ergon. Manuf. Serv. Ind. 2017, 27, 171-176. [CrossRef] 
27. Chen, C.-Y.; Cho, M.-H.; Lin, Y.-H.; Chao, K.-C. The influence of prolonged standing on subjective discomfort and shank circumference on different foot/floor interface. J. Occup. Saf. Health 2009, 17, 335-342. [CrossRef]

28. Howell, J.N.; Chila, A.G.; Ford, G.; David, D.; Gates, T. An electromyographic study of elbow motion during postexercise muscle soreness. J. Appl. Physiol. 1985, 58, 1713-1718. [CrossRef]

29. Smith, L.L. Acute inflammation: The underlying mechanism in delayed onset muscle soreness? Med. Sci. Sports Exerc. 1991, 23, 542-551. [CrossRef]

30. World Medical Association. World Medical Association Declaration of Helsinki: Ethical principles for medical research involving human subjects. JAMA 2013, 310, 2191-2194. [CrossRef] [PubMed]

31. López-Miñarro, P.A.; Muyor, J.M.; Belmonte, F.; Alacid, F. Acute effects of hamstring stretching on sagittal spinal curvatures and pelvic tilt. J. Hum. Kinet. 2012, 31, 69-78. [CrossRef]

32. Decoster, L.C.; Scanlon, R.L.; Horn, K.D.; Cleland, J. Standing and supine hamstring stretching are equally effective. J. Athl. Train. 2004, 39, 330-334. Available online: www.ncbi.nlm.nih.gov/pmc/articles/PMC535525/ (accessed on 13 June 2021).

33. Dash, S.S. Efficacy of supine, sitting and standing hamstring stretch positions on flexibility in college students: A randomised experimental study. Indian J. Physiother. Occup. Ther. 2020, 14, 197-202. [CrossRef]

34. Marshall, P.W.; Cashman, A.; Cheema, B.S. A randomized controlled trial for the effect of passive stretching on measures of hamstring extensibility, passive stiffness, strength, and stretch tolerance. J. Sci. Med. Sport 2011, 14, 535-540. [CrossRef]

35. Eungpinichpong, W.; Buttagat, V.; Areeudomwong, P.; Pramodhyakul, N.; Swangnetr, M.; Kaber, D.; Puntumetakul, R. Effects of restrictive clothing on lumbar range of motion and trunk muscle activity in young adult worker manual materials handling. Appl. Ergon. 2013, 44, 1024-1032. [CrossRef] [PubMed]

36. Mündermann, A.; Nigg, B.M.; Stefanyshyn, D.J.; Humble, R.N. Development of a reliable method to assess footwear comfort during running. Gait Posture 2002, 16, 38-45. [CrossRef]

37. Kinugasa, T.; Kilding, A.E. A comparison of post-match recovery strategies in youth soccer players. J. Strength Cond. Res. 2009, 23, 1402-1407. [CrossRef]

38. Herbert, R.D.; de Noronha, M.; Kamper, S.J. Stretching to prevent or reduce muscle soreness after exercise. Cochrane Database Syst. Rev. 2011, 7, CD004577. [CrossRef] 